\title{
Biocompatible Unimolecular Micelles Obtained via the Passerini Reaction as Versatile Nanocarriers for Potential Medical Applications
}

\author{
Stefan Oelmann, ${ }^{\dagger, \ddagger}$ Alessandra Travanut, ${ }^{\ddagger},{ }^{\prime}, \#$ Dennis Barther, ${ }^{\dagger}$ Manuel Romero, ${ }^{\|, \#}$ Steven M. Howdle, ${ }^{\perp, \# \odot ~}$

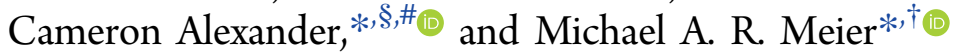 \\ ${ }^{\dagger}$ Institute of Organic Chemistry (IOC), Materialwissenschaftliches Zentrum (MZE), Karlsruhe Institute of Technology (KIT), \\ Straße am Forum 7, 76131 Karlsruhe, Germany \\ ${ }^{\S}$ Molecular Therapeutics and Formulation Division, School of Pharmacy, "School of Life Sciences, Centre for Biomolecular Sciences, \\ ${ }^{\perp}$ School of Chemistry, and ${ }^{\#}$ EPSRC Programme Grant in Next Generation Biomaterials Discovery (NGBD), School of Pharmacy, \\ The University of Nottingham, University Park, NG72RD, Nottingham United Kingdom
}

Supporting Information

ABSTRACT: A Passerini three-component polymerization was performed for the synthesis of amphiphilic star-shaped block copolymers with hydrophobic cores and hydrophilic coronae. The degree of polymerization of the hydrophobic core was varied from 5 to 10 repeating units, and the side chain ends were conjugated by performing a Passerini-3CR with PEG-isocyanide and PEG-aldehyde $(950 \mathrm{~g} / \mathrm{mol})$. The resulting amphiphilic star-shaped block copolymers contained thioether groups, which could be oxidized to sulfones in order to further tune the polarity of the polymer chains. The ability of the amphiphilic copolymers to act as unimolecular micellar encapsulants was tested with the water-insoluble dye Orange II, the water-soluble dye Para Red and the macrolide antibiotic azithromycin. The results showed that the new copolymers were able to retain drug cargo at $\mathrm{pH}$ levels corresponding to circulating blood and selectively release therapeutically effective doses of antibiotic as measured by bacterial cell kill. The polymers were also well-tolerated by differentiated THP-1 macrophages in the absence of encapsulated drugs.

\section{INTRODUCTION}

Multicomponent reactions are popular, well-established, and highly efficient reactions, due to their high atom economy, the easy synthesis protocols, and finally, the large achievable structural variation. ${ }^{1,2}$ Multicomponent reactions combine three or more starting materials to form a single product under usually very mild conditions in a one-pot procedure., ${ }^{3,4}$ One of the most established multicomponent reactions is the Passerinithree component reaction (Passerini-3CR), discovered by Mario Passerini in 1921, which to date has been mainly employed in medicinal and combinatorial chemistry. ${ }^{5}$ The Passerini-3CR combines a carboxylic acid, an oxo component (aldehyde or ketone) and an isocyanide to synthesize an $\alpha$-acyloxycarboxamide. The use of monomers having two functional groups (e.g., $\mathrm{AA}+\mathrm{BB}$ or $\mathrm{AB}$ monomers) in a Passerini-3CR can lead to the formation of polymers, which was investigated for the first time by Meier et al. ${ }^{7}$ By using this addition polymerization, which follows a classic step-growth polymerization mechanism, polyesters and polyamides with functional side chains, depending on the monomer combinations, can be obtained. ${ }^{8,9}$ An important advantage of this multicomponent polymerization technique is the highly flexible choice of side chains and thus the adjustment of the properties of the obtained polymers.

The topic of well-defined polymer synthesis and their applications is of high interest and can be performed via

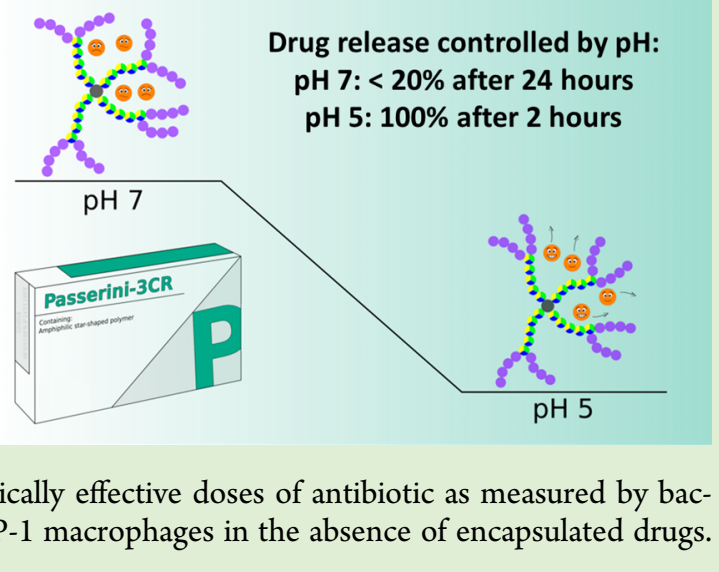

multicomponent reactions, due to their efficiency, modular nature, and the simple reaction conditions. Star-shaped polymers, which can be defined as polymers having a defined number of arms (and accordingly end groups) covalently bound to a defined organic center molecule, ${ }^{10,11}$ are an important class of highly defined macromolecules, which can, for instance, be used as unimolecular micelles for applications as catalysts or as hosts for low molecular weight organic guest molecules. ${ }^{12}$ Interestingly, unimolecular micelles can retain good stability under extreme environmental changes and consequently, are considered more stable than the conventional supramolecular micelles. ${ }^{13}$ For example, Shen et al. developed an aliphatic polyester derived dendrimer by performing thiol/acrylate click reactions and esterifications, followed by a final PEGylation. ${ }^{13}$ The obtained water-soluble biocompatible unimolecular micelles were able to encapsulate and release hydrophobic anticancer drugs. Furthermore, Pang et al. synthesized a 21-arm star-like copolymer with hydrophilic poly(acrylicacid) blocks and hydrophobic polystyrene core by performing a sequential

Special Issue: Biomacromolecules BPC

Received: April 9, 2018

Revised: $\quad$ May 25, 2018

Published: June 5, 2018 
ATRP of $t$-butyl acrylate and styrene and $21 \mathrm{Br}-\beta-\mathrm{CD}$ as macroinitiator. ${ }^{13}$ They showed how the unimolecular micelle's size could be tuned by controlling the molecular weight of each block of the star-like copolymer. Recently, the group of Meier developed a versatile new approach to synthesize amphiphilic star-shaped block copolymers, controlling their molecular weight and with $100 \%$ end group fidelity in a straightforward fashion using the Passerini-3CR. ${ }^{14}$ Furthermore, the encapsulation of water-insoluble and water-soluble guest molecules, as well as the phase transfer of these multifunctional materials from water to an organic phase, were investigated. ${ }^{15}$

Within this work, we extend this encapsulation study by varying the polarity of the core of the star-shaped block copolymers as well as the number of arms of these unimolecular micelles, and utilize the resultant materials to encapsulate and release an antimicrobial agent, azithromycin. We could thus unambiguously demonstrate that a matching of the polarity of the guest molecule with the core of our unimolecular micelles leads to improved encapsulation, thus significantly enhancing the understanding of the studied system and unimolecular micelles in general. Polymer syntheses were performed via the Passerini3CR and by using different isocyanides and core molecules within the Passerini-3CR, as well as oxidizing the sulfides to sulfones in the backbone of the polymers. Thus, the polarity as well as the architecture of the resulting star-shaped polymers were adjusted. As exemplars for the ability of these polymers to encapsulate a variety of active molecules, Orange II, Para Red, and azithromycin were incorporated as guest molecules in formulations with the Passerini-3CR polymers. The data from encapsulation and release experiments clearly suggested the investigated unimolecular micelles showed promise as potential drug delivery systems, due to their good drug loading capacities and controlled release properties. In addition, as Passerini-3CR polymers are biodegradable polyesters, these results imply that developed materials of this class may find widespread future use as active carrier and release agents in a range of biomedical applications.

\section{EXPERIMENTAL SECTION}

Materials and Methods. The following chemicals were used as received: 10-Undecenal ( $\geq 90 \%$, Aldrich), 3-mercaptopropionic acid ( $\geq 99 \%$, Aldrich), 2,2-dimethoxy-2-phenylacetophenone (DMPA, 99\%, Aldrich), tert-butyl isocyanide ( $98 \%$, Aldrich), benzyl isocyanide (98\%, Aldrich), tert-butyl 2-isocyanoacetate (98\%, Aldrich), trimesic acid (95\%, Aldrich), O-methyl-O'-[2-(6-oxocaproylamino)ethyl]polyethylene glycol 2000, (PEG aldehyde 2000, Aldrich), 11-aminoundecanoic acid (97\%, Aldrich), methanol (99\%, Aldrich), thionyl chloride (97\%, Aldrich), trimethyl orthoformate (99\%, Aldrich), diisopropyl amine (99\%, Aldrich), phosphorus(V) oxychloride (99\%, Aldrich), 1,5,7-triazabicyclo[4.4.0] dec-5-ene (TBD, 98\%, Aldrich), poly(ethylene glycol) methyl ether 750 (Methoxy PEG 750, Aldrich), poly(ethylene glycol) methyl ether thiol 800 (PEG thiol 800 , Aldrich), Orange II sodium salt ( $85 \%$ dye content, Aldrich), Para Red (95\% dye content, Aldrich), Reichardt's dye (90\%, Aldrich), 3-chloroperbenzoic acid ( $m$ CPBA, 77\%, Aldrich), hydrogen peroxide solution ( $30 \%$ in water, Aldrich), methyl isocyanoacetate (95\%, Aldrich), 3,3,5,5-tetracarboxydiphenylmethane (95\%, Aldrich), silica gel 60 (0.035-0.070, Aldrich), chloroform- $d\left(\mathrm{CDCl}_{3}, 99.8\right.$ atom-\% $\mathrm{D}$, euriso-top), methanol- $d_{4}$ (99,8 atom-\% D, euriso-top), CellTiter-Fluor Cell Viability Assay (Promega, Madison WI), azithromycin (PHR1088, Aldrich), Tween 20 (P1379, Aldrich), Dulbecco's Phosphate Buffered Saline, PBS (Aldrich), citric acid (C-3674, Aldrich), Phorbol 12-myristate 13-acetate (PMA; 99\%, Aldrich), penicillin/streptomycin (Aldrich), L-glutamine (Aldrich), THP-1 human cells were purchased from ATCC in frozen form (Manassas, VI, U.S.A.), RPMI-1640 media and fetal bovine serum were obtained from Life Technologies (Carlsbad, CA, U.S.A.). All solvents used were of technical grade.

Synthesis of Amphiphilic Three-Armed Star-Shaped Block Copolymers. Part I: Synthesis of Star-Shaped Homopolymers P1, $P 2$, and $P 3$. The $\mathrm{AB}$-type monomer 3 , containing a carboxylic acid and an aldehyde end group, was synthesized via a thiol-ene reaction, using 10-undecenal $\mathbf{1}$ and 3-mercaptopropionic acid 2 (Supporting Information (SI), page 5). ${ }^{14}$ By using ratios of $15: 1$ and 30:1 of monomer 3 and a trifunctional carboxylic acid as an irreversible chain transfer agent 4 (ICTA) and an excess of tert-butyl isocyanide 5, starshaped polymers P1 and P2 with a degree of polymerization of 5 and 10 per arm (i.e., 5 and 10 repeating units per arm) were prepared. The use of methyl isocyanoacetate $\mathbf{6}$ as isocyanide component under the same conditions led to polymer $\mathbf{P 3}$.

Part II: P1, P2, and P3 Homopolymers Functionalization to Amphiphilic Star-Shaped Block Copolymers P4, P5, and P6. The end groups of the star-shaped homopolymers P1, P2, and P3 were functionalized by a further Passerini-3CR using a PEG isocyanide 7 and a PEG aldehyde 8 . The reactant PEG isocyanide 7 was prepared by end-group modification of methoxy PEG 17 via a transesterification with isocyanide $\mathbf{1 6}$. The three-step synthesis of isocyanide $\mathbf{1 6}$ starting from amine $\mathbf{1 0}$ is known in literature. First, methyl ester $\mathbf{1 2}$ is obtained and afterward formamide $\mathbf{1 4}$ is formed, which is finally converted to isocyanide 16 (SI, Scheme S1). ${ }^{16}$ The PEG aldehyde 8 was synthesized via a thiol-ene reaction of 10-undecenal 1 with a commercially available PEG thiol 18 (SI, Scheme S2).

Part III: Oxidation of P4 and P6 Star-Shaped Block Copolymers to P7 and P8. The sulfur containing backbones of the star-shaped block copolymers P4 and P6 were oxidized using two different procedures to obtain star-shaped polymers $\mathbf{P 7}$ and $\mathbf{P 8}$ with a higher polarity. In the first procedure, 3-chloroperbenzoic acid ( $m \mathrm{CPBA}$ ) was used as oxidizing agent at room temperature. In a more sustainable way, hydrogen peroxide was used at a higher temperature of $60{ }^{\circ} \mathrm{C}$ (SI, pages 11-13).

Synthesis of Amphiphilic Four-Armed Star-Shaped Block Copolymers. Using a different four-armed ICTA (3,3'5,5'tetracarboxydiphenylmethane 9) via the same method described in the previous Part I and Part II, four-armed star-shaped homopolymers P9-P12 with different number of repeating units, four-armed starshaped homopolymer P13 with more polar side chains and functionalized, amphiphilic four-armed star-shaped copolymer P14 were synthesized (SI, pages 13-16).

Characterization of the Unimolecularity of the Star-Shaped Block Copolymers via DLS. Dynamic light scattering (DLS) of the star-shaped block copolymers P6, P7, P8, and P14 was measured and compared in a concentration of $1.0 \mathrm{mg} / \mathrm{mL}$ in water and DCM to confirm the unimolecularity and to exclude the formation of aggregates (SI, Figures S24-S27).

Polarity Characterization and Dye Encapsulation Tests of Three-Armed Star-Shaped Polymers. Part I: Octanol-Water Partition Coefficient. The octanol-water partition coefficients $(P)$ of the reduced and oxidized star-shaped copolymers P4, P6, P7, and P8 and two dyes (Orange II and Para Red) were determined. The octanolwater partition coefficient $(P)$ directly correlates with the polarity of the chemical substrates. An easy and fast method to obtain the polarity of a substance is the indirect determination of partition coefficients from chromatographic retention data, using the reverse phase HPLC (RP-HPLC) method. ${ }^{17}$ Therefore, octanol was displaced by a mixture of methanol and water (70:30) as eluent. ${ }^{18}$ The HPLC system was calibrated with different substances of known $P .{ }^{19}$ To determine the dead time of the column, which is defined as the time needed for a compound not interacting with the stationary phase while passing the column $\left(t_{0}\right)$, thiourea was chosen. By using $t_{0}$ and $t$ (retention time of the polymers), the capacity factor $k$, which is described as the retention of a substance, can be calculated and is defined as followed:

$$
k=\frac{t-t_{0}}{t_{0}}
$$

The linear relation between $k$ and the octanol-water partition coefficient enabled the experimental value of $P$ to be easily determined. 
Scheme 1. Synthesis of AB-Type Monomer 3 and Subsequent Polymerization Using Different Ratios of AB-Type Monomer 3 and Trifunctional ICTA 4 and Different Isocyanides 5 and 6 To Obtain Star-Shaped Homopolymers P1, P2, and P3

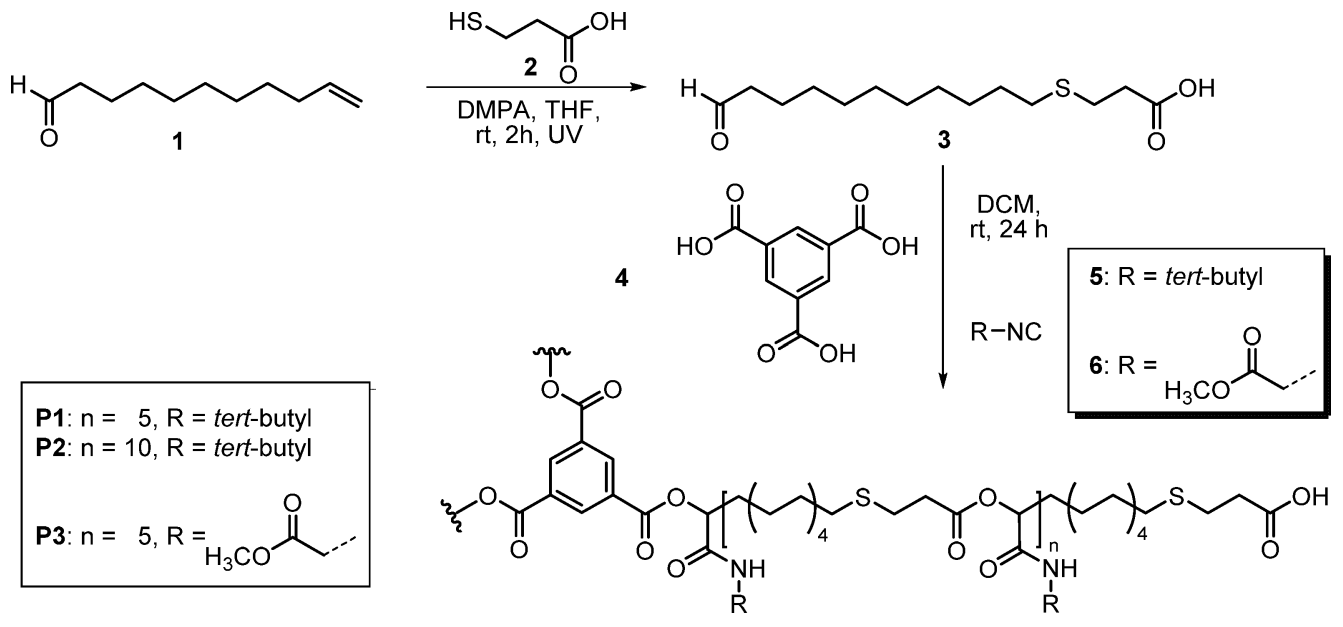

Part II: Orange II and Para Red Encapsulations Determined by UV/Vis Measurements. An excess of 10 molecules Orange II per starshaped polymer molecule $(5.00 \mathrm{mg})$ was added to $5.00 \mathrm{~mL}$ DCM, in which it is not soluble. After addition of the star-shaped polymer, the dye was encapsulated and dissolved in DCM (i.e., within the core of the star-shaped block copolymer). Afterward, the nonencapsulated dye molecules were filtered off and the UV/vis absorption of the resultant orange solution was carried out. The test was performed with the reduced and oxidized three-armed star-shaped block copolymers P4, P6, P7, and P8. The same preparation and measurement was repeated using water-insoluble Para Red as dye in water.

Part III: Reichardt's Dye Solvatochromism Tests. The Reichardt's dye was encapsulated (one molecule per star-shaped polymer) in $5.00 \mathrm{~mL} \mathrm{DCM}$, the UV/vis absorption was measured, using $5.00 \mathrm{mg}$ of the reduced and oxidized three-armed star-shaped block copolymers P4, P6, P7, and P8 and the wavelength maxima were compared.

Comparison of the Encapsulation Behavior of Four-Armed and Three-Armed Star-Shaped Polymers. Orange II was added to $10.0 \mathrm{~mL}$ of a water/DCM biphasic system. Orange II was soluble in the water phase, but not in the DCM phase. After addition of fourarmed star-shaped block copolymer P14 and shaking, the dye was encapsulated and phase-transferred to the DCM phase. In both phases, the absorption was measured separately using UV/vis and compared to previously obtained results of amphiphilic three-armed star-shaped block copolymer P4. ${ }^{14}$

Drug Loading and Encapsulation Efficiency. A $100 \mathrm{mg} / \mathrm{mL}$ solution of star-shaped block copolymers in THF was mixed with a $100 \mathrm{mg} / \mathrm{mL}$ solution of azithromycin in THF, molecular ratio of $1: 10$, and introduced into 10 volumes of deionized water under vigorous stirring. The organic solvent was removed using a rotary evaporator and the solution was centrifuged for $5 \mathrm{~min}$ at $14000 \mathrm{rpm}$. The supernatant containing the azithromycin loaded star-shaped block copolymers micelles was removed and freeze-dried, whereas the unloaded waterinsoluble azithromycin was collected, solubilized in ACN/water solution (1:1) and quantified by UV/vis spectrophotometry at $210 \mathrm{~nm}^{20}$ referring to a standard calibration curve (SI, Figure S28). The total amount of drug was determined by preparing in parallel a polymer free sample with an equal content of azithromycin. The amount of loaded drug was calculated by difference. The estimation of drug loading and encapsulation efficiency are mentioned in the SI, page 32.

In Vitro Drug Release Study. Drug release studies were performed in phosphate-buffered saline (PBS with $0.1 \%$ Tween 20 ) at $\mathrm{pH} 7.4$ (blood $\mathrm{pH})^{21}$ and citrate phosphate buffer $(0.1 \mathrm{M}$ citric acid, $0.2 \mathrm{M} \mathrm{Na}_{2} \mathrm{HPO}_{4}$ and $0.1 \%$ Tween 20$)^{22}$ at pH 5 (lysosome $\mathrm{pH}$ ). A sample $(5 \mathrm{mg})$ of azithromycin loaded and freeze-dried $\mathbf{P} 14$ micelles (see drug loading and encapsulation efficiency paragraph) were dispersed in $0.5 \mathrm{~mL}$ of release media and the solution was placed in a dialysis device (Slide-A-Lyzer mini dialysis device, 3.5 K MWCO,
Thermo Scientific). The micellar solution was dialyzed against $1.5 \mathrm{~mL}$ of release media at $37{ }^{\circ} \mathrm{C}$ and samples $(0.2 \mathrm{~mL})$ were taken at appropriate time points and replaced with $0.2 \mathrm{~mL}$ of fresh medium. ${ }^{23}$ The collected samples were diluted with the same volume of ACN and the released azithromycin was quantified by UV/vis spectrophotometry at $210 \mathrm{~nm}$ referring to a standard calibration curve (SI, Figure S28). The cumulative release (\%) was defined based on the concentration of azithromycin calculated in the samples collected at different time points and considering the initial amount of encapsulated drug into the micelles.

Cell Culture. THP-1 cells (a human monocytic cell line) were cultured in RPMI 1640 media supplemented with $10 \%$ fetal bovine serum, $5 \%$ penicillin/streptomycin and 5\% L-glutamine. To differentiate the monocytes to macrophages, cells were treated with $50 \mathrm{ng} / \mathrm{mL}$ of PMA, which is dissolved in medium, for $24 \mathrm{~h}$ at $37{ }^{\circ} \mathrm{C}, 5 \% \mathrm{CO}_{2} .{ }^{24}$ Cells were differentiated at $7.5 \times 10^{5} \mathrm{THP}-1$ cells $/ \mathrm{mL} /$ well in 96 -well tissue cultured-treated polystyrene plates (Corning Life Sciences).

Viability Assay. CellTiter-Fluor cell viability Assay was performed to determine the cytotoxicity ${ }^{25}$ of $\mathbf{P 1 4}$ against macrophage differentiated cells following the protocol provided by the vendor (Promega, Madison WI). Cells were treated for $72 \mathrm{~h}$ with different concentrations of P14. The procedure is mentioned in the SI, pages 33-34.

Bacterial Susceptibility Assay. To evaluate the bacteriostatic activity of azithromycin loaded unimolecular P14 micelles, free, or encapsulated azithromycin were tested at drug concentrations of $0.1,1$, 10, and $100 \mathrm{ug} / \mathrm{mL}$ against Staphyloccocus aureus SH1000 cultures. Bacteria were grown overnight in tryptic soy broth (TSB Difco). The next day, the optical density $\left(\mathrm{OD}_{600}\right)$ of the culture was adjusted to 0.01 in fresh TSB and $200 \mathrm{uL}$ aliquots of the culture supplemented with antibiotic were loaded in wells of a microtiter plate. As controls, untreated wells, and wells supplemented with solvent or polymer, were set. Bacterial growth was monitored for $24 \mathrm{~h}$ at $37^{\circ} \mathrm{C}$ using a 96-well plate TECAN Genios Pro spectrophotometer (Tecan, U.K.). The minimum inhibitory concentration (MIC) was defined as the antibiotic concentration where no visible bacterial growth was observed or the OD 600 was $<10 \%$ compared to the untreated control after $24 \mathrm{~h}$ of antibiotic exposure.

Cellular Uptake Study. Oregon-green loaded P14 unimolecular micelles were prepared by mixing $0.1 \mathrm{~mL}$ of a $100 \mathrm{mg} / \mathrm{mL} \mathrm{P14} \mathrm{solu-}$ tion in THF with $0.03 \mathrm{~mL}$ of a $28 \mathrm{mg} / \mathrm{mL}$ solution of Oregon-green in DMSO, molecular ratio of $1: 3$, and introduced into 10 volumes of deionized water under vigorous stirring. The solution was purified by dialysis for 3 days against $5 \mathrm{~L}$ of deionized water using a cellulose dialysis membrane (Thermofisher, cutoff 3500 ) to remove the organic solvents and the free Oregon-green. The solution was then sterilized by filtration $(0.22 \mu \mathrm{m}$, Millipore filters $)$. For cellular uptake studies, THP-1 cells $\left(3 \times 10^{5}\right.$ cells per well $)$ were differentiated in an 8-well glass bottom $\mu$-slide (ibidi, Germany) for $24 \mathrm{~h}$ at $37^{\circ} \mathrm{C}, 5 \% \mathrm{CO}_{2}$. Cell medium was removed and cells were then treated with fresh medium 
Scheme 2. Functionalization of P1, P2, and P3 with PEG Isocyanides 7 (950 g/mol) and PEG Aldehyde 8 (950 g/mol) to Obtain Amphiphilic Star-Shaped Block Copolymers P4, P5, and P6

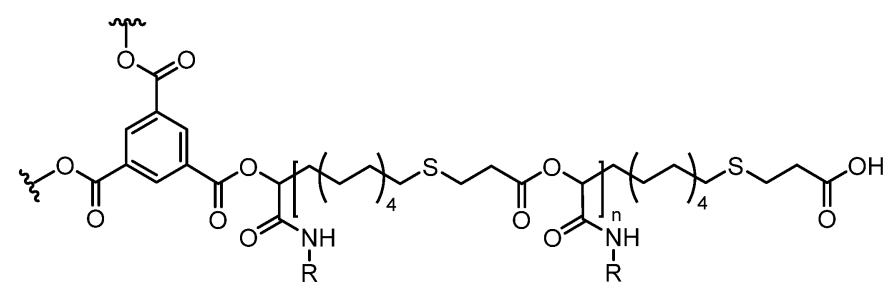

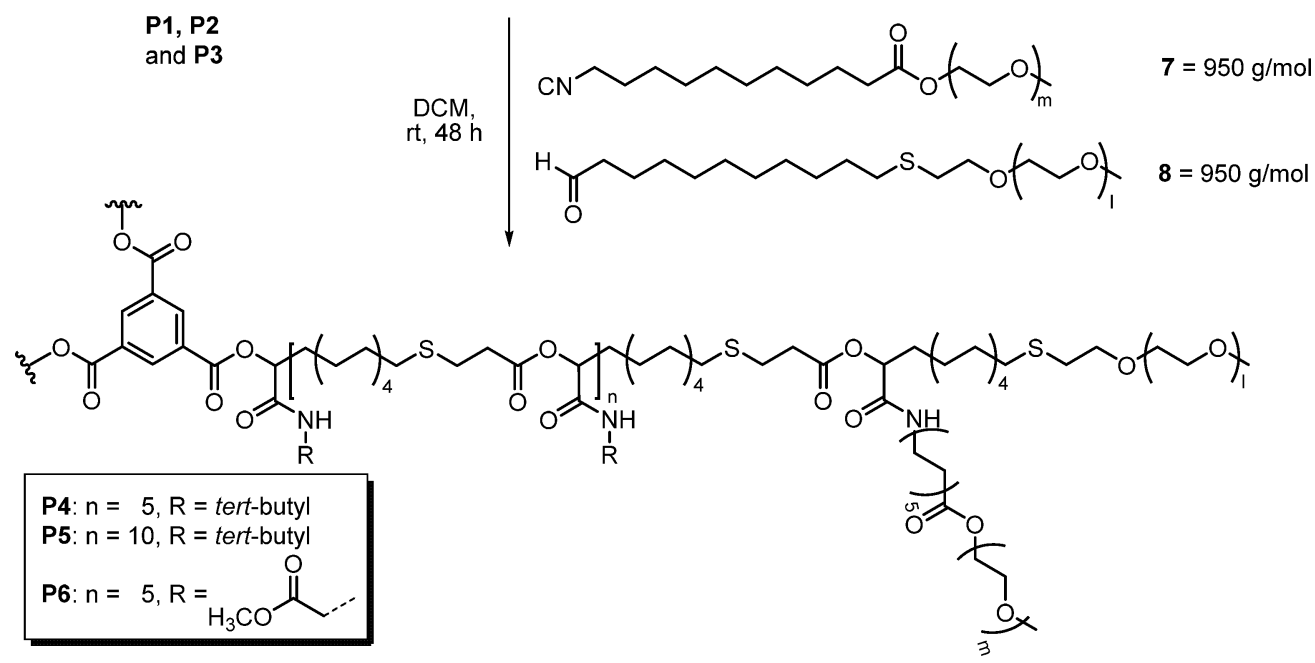

Scheme 3. Oxidation Procedures of Star-Shaped Block Copolymers P4 and P6 with $m$ CPBA or Hydrogen Peroxide to Sulfone Analogues P7 and P8

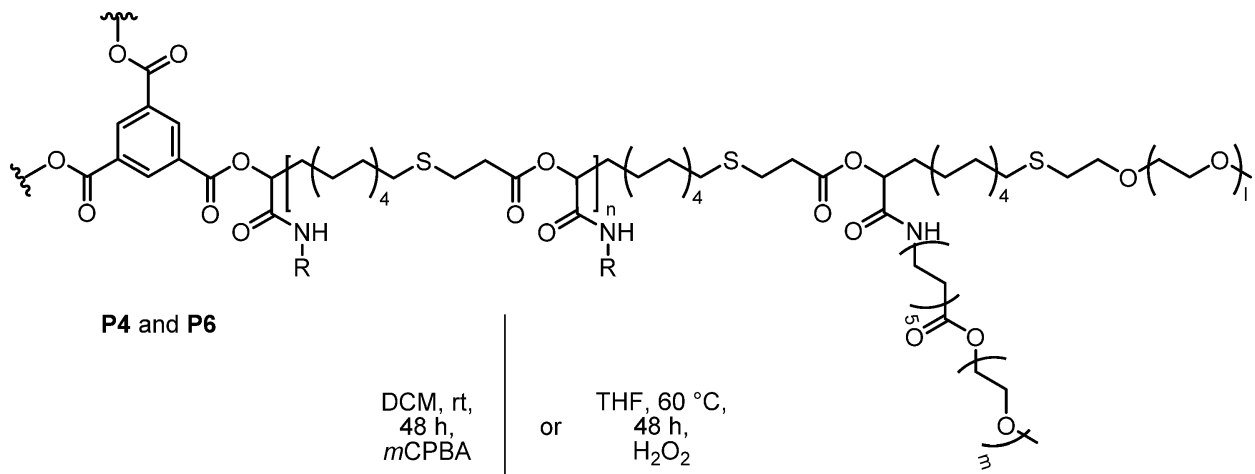

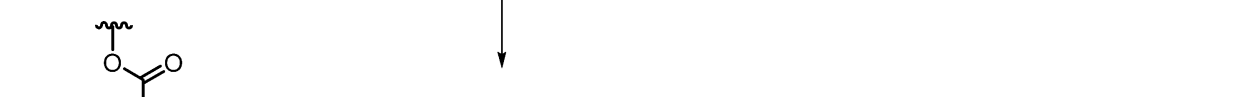

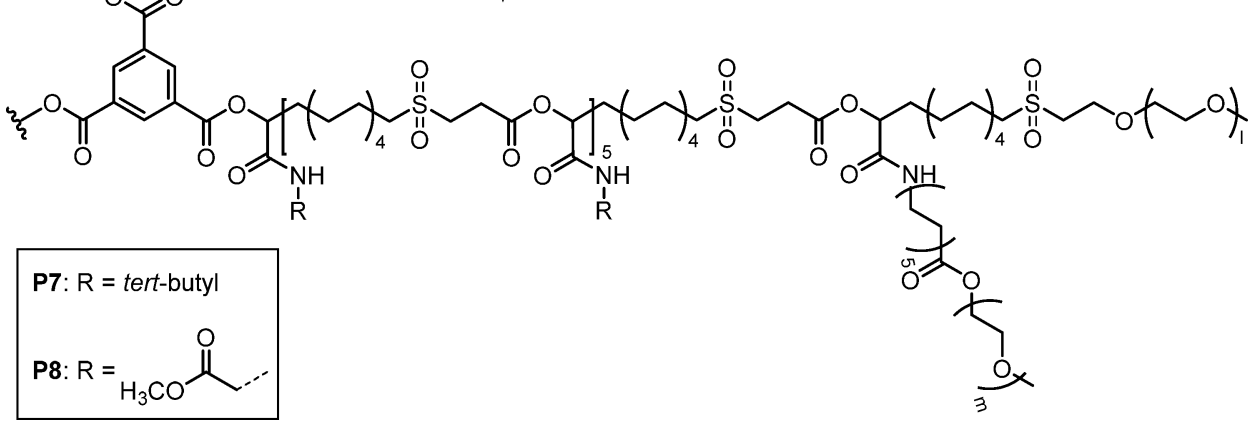

containing Oregon-green $(100 \mu \mathrm{g} / \mathrm{mL})$ loaded P14 unimolecular micelles and incubated for $1 \mathrm{~h}^{26}$ Cells nuclei were stained with Hoechst 33342 dye $(1 \mu \mathrm{g} / \mathrm{mL}$, ThermoFisher $)$. F-actin was stained with Alexa Fluor 647 Phalloidin $(1 \mu \mathrm{g} / \mathrm{mL}$, ThermoFisher) or alternatively the cells membrane was stained with deep red CellMask (1 $\mu \mathrm{g} / \mathrm{mL}$, Life Technologies). Finally, cells were covered with PBS and examined using a Carl Zeiss LSM 700 BW microscope. The detailed staining protocol is mentioned in SI, pages $35-37$.

\section{RESULTS AND DISCUSSION}

Synthesis of Amphiphilic Three-Armed Star-Shaped Block Copolymers. The synthesis of star-shaped homopolymers 


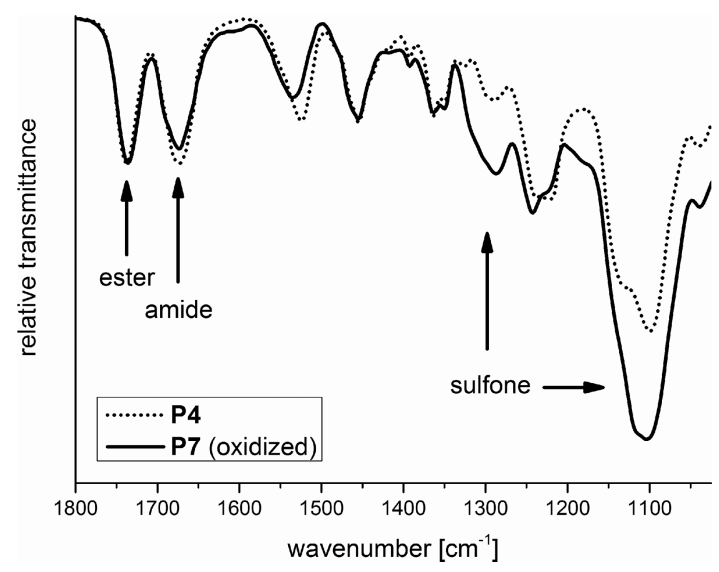

Figure 1. IR spectra (ATR) of the relevant region of reduced and oxidized three-armed star-shaped block copolymers P4 and P7.

with controlled molar masses is based on the introduction of a trifunctional carboxylic acid as an irreversible chain transfer agent 4 (ICTA) in a polymerization process of an AB-type monomer 3 (combination of carboxylic acid and aldehyde) and an excess of isocyanide (Scheme 1). ${ }^{14}$ The ratio of ICTA 4 to $\mathrm{AB}$-type monomer 3 enables the prediction of the molar masses of the obtained polymers comparable with the initiator to monomer ratio in living controlled polymerization techniques.
In order to investigate the encapsulation behavior of the polymers, two star-shaped homopolymers with different numbers of repeating units were synthesized (5 and 10 repeating units per arm), using ratios of 15:1 and 30:1 of monomer 3 and ICT 4. The symmetric molecular weight distributions (SI, Figure S21) and the molecular weights obtained by ${ }^{1} \mathrm{H}$ NMR end group integration, which were comparable to the calculated molecular weights (SI, Figures S2 and S3, Formula S1, and Table S1), confirmed complete monomer conversion and the expected degrees of polymerization. In order to change the polarity of the star-shaped polymers in a straightforward fashion, methyl isocyanoacetate $\mathbf{6}$ was used as isocyanide component with the same degree of polymerization as P1, which leads to star-shaped polymer $\mathbf{P} 3$, providing more polar side chains.

In order to obtain amphiphilic star-shaped block copolymers showing unimolecular micellar behavior, P1, P2, and P3 were post-modified applying the conditions examined in previous studies ${ }^{1}$ using a water-soluble PEG-based (polyethylene glycol) shell (Scheme 2). Therefore, the carboxylic acid end groups of the star-shaped homopolymers were reacted with a previously synthesized PEG aldehyde 8 (950 g/mol) and a PEG isocyanide 7 $(950 \mathrm{~g} / \mathrm{mol})$ to form a water-soluble shell owing to two PEG chains attached to the arms, leading to amphiphilic star-shaped block copolymers P4, P5, and P6. ${ }^{1} \mathrm{H}$ NMR end group integration again confirmed full conversion to the desired products (SI, Figures S10-S12).

Scheme 4. Synthesis of Different Four-Armed Star-Shaped Homopolymers and the Following Functionalization to Obtain Amphiphilic Four-Armed Star-Shaped Copolymer P14

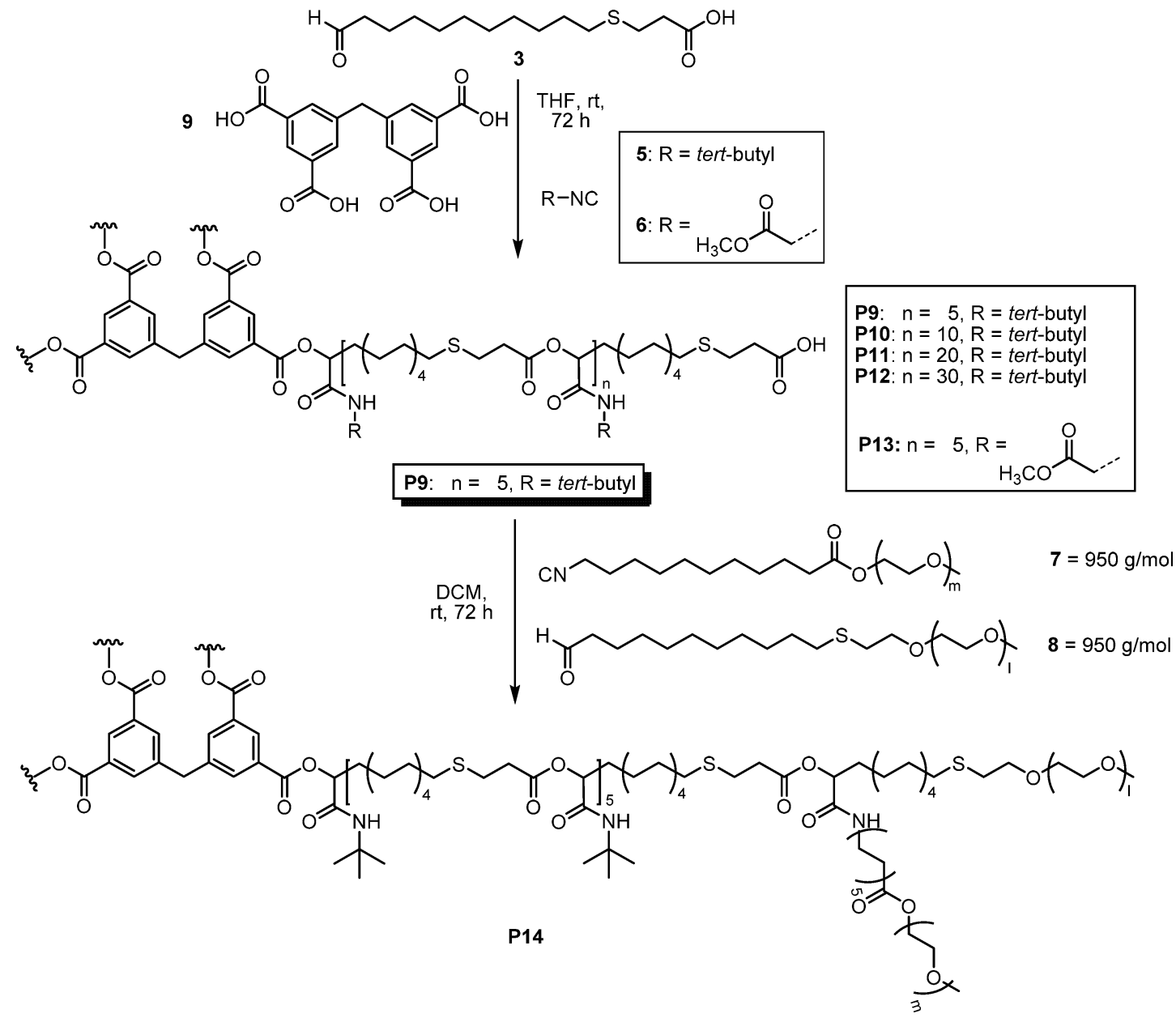


In comparison to common less polar thioethers, sulfones in general show a higher polarity. Interestingly, in this case, the synthesized star-shaped block copolymers have a sulfur containing backbone and it is known that thioethers can be easily oxidized to sulfones using oxidation reagents such as 3-chloroperbenzoic acid ( $m$ CPBA) or hydrogen peroxide. ${ }^{27,28}$ Consequently, besides the choice of the isocyanide, the polarity could be adjusted according to the desired application by simply oxidizing the polymers. The oxidation of P4 and P6 proceeded readily leading to star-shaped block copolymers P7 and P8 with an increased polarity (Scheme 3). Subsequent ${ }^{1} \mathrm{H}$ NMR analysis of the obtained polymers confirmed a successful oxidation of each sulfur atom. The neighboring protons to the sulfur showed a shift toward higher ppm values, while all the other signals remained unchanged (SI, Figures S13 and S14).

Furthermore, IR spectra of the reduced and oxidized starshaped block copolymers P4 and P7 were recorded and compared, also confirming the oxidation reaction and sulfoxide formation (Figure 1). In principle, sulfoxides absorb at a region of $1030-1060 \mathrm{~cm}^{-1}$, while sulfones show characteristic absorptions at $1120-1260 \mathrm{~cm}^{-1}$ and $1300-1350 \mathrm{~cm}^{-1}$. For polymer P7 a strong absorption at $1120 \mathrm{~cm}^{-1}$ and a broad intensive band between 1270 and $1330 \mathrm{~cm}^{-1}$ were detected, in contrast with the absorptions of the starting polymer P4. Since in the region of sulfoxide absorption no bands were detected, an indication of full conversion to the corresponding sulfone was confirmed. Together with the ${ }^{1} \mathrm{H}$ NMR results, it can be assumed that the conversion was completely.

Synthesis of Amphiphilic Four-Armed Star-Shaped Block Copolymers. Furthermore, it was shown that, in addition to the variation of the polarity for the desired unimolecular micellar behavior, the number of arms of the star-shaped polymers is highly relevant. Therefore, a star-shaped polymer with four arms was synthesized. In this case, a suitable irreversible chain transfer agent should contain four carboxylic acid end groups to form the four-armed star-shaped polymers. In order to determine their length by ${ }^{1} \mathrm{H}$ NMR spectroscopy, it was advantageous that the irreversible chain transfer agent (ICTA) compound used in the synthesis contained aromatic protons. These protons did not overlap with those of the backbone, due to their high ppm values, whereby the ratio of the protons between the core and repeating unit could be determined exactly. Furthermore, it was of high importance that the corresponding

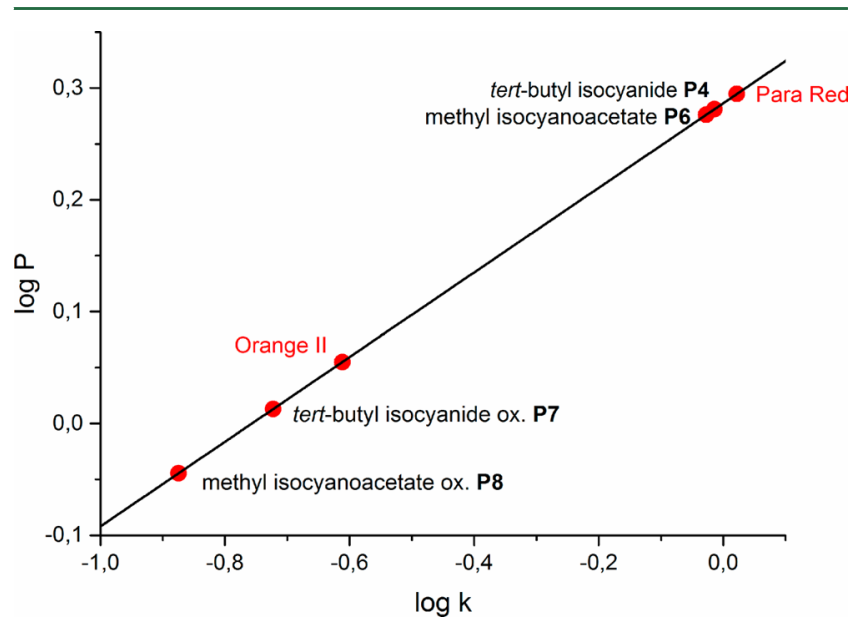

Figure 2. RP-HPLC determination of octanol-water partition coefficients of reduced and oxidized three-armed star-shaped block copolymers P4, P6, P7, and P8 compared with Orange II and Para Red.
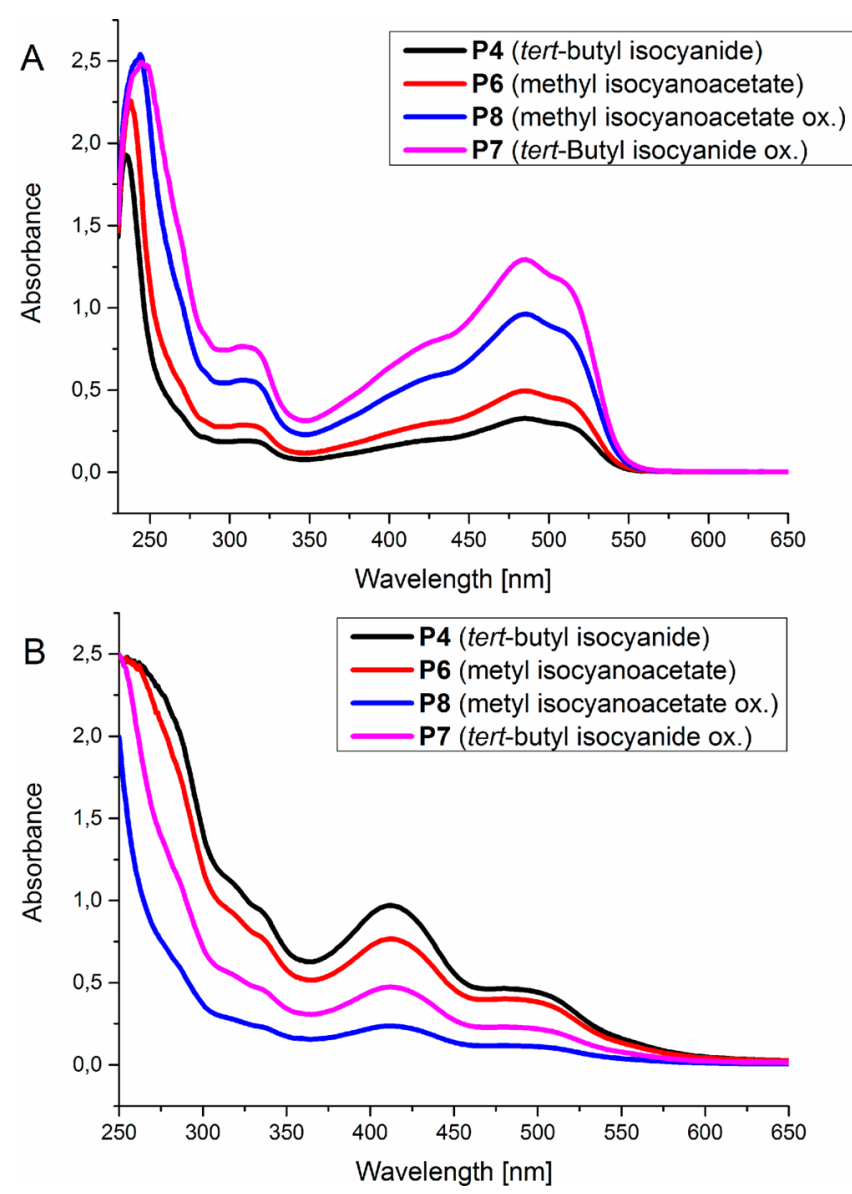

Figure 3. UV/vis spectra of the encapsulation of (A) Orange II in DCM by reduced and oxidized star-shaped block copolymers P4, P6, P7, and P8; (B) water insoluble Para Red in water by reduced and oxidized star-shaped block copolymers P4, P6, P7, and P8.

ICTA had a good solubility in the corresponding solvent. Therefore, 3,3'5,5' -tetracarboxydiphenylmethane 9 was chosen as the most suitable ICTA. Due to the good solubility, the reaction with the four-armed ICTA 9 was carried out in THF. The reaction time had to be increased to $72 \mathrm{~h}$ (Scheme 4). Again, by performing this reaction, it was shown that the number of repeating units can be varied selectively and easily by varying the ratio of ICTA 9 to AB-type monomer 3. Different four-armed star-shaped homopolymers with five repeating units per arm $([3]:[9], 1: 5$ per arm P9) and with 10, 20, and 30 repeating units per arm ([3]:[9], 1:10 P10, 1:20 P11, 1:30 P12 per arm) could be synthesized. It was also shown that the symmetric molecular weight distribution shifts toward smaller retention times with increasing arm length or with increasing hydrodynamic radius, respectively (SI, Figure S22). ${ }^{1} \mathrm{H}$ NMR analysis of the resulting polymers P9-P12 showed an excellent correlation of the aromatic proton signals of the ICTA and the signals of the repeating units (SI, Figures S15-S18 and Table S2). Additionally, it was shown that it is also possible for four-armed star-shaped polymers to be obtained with different side groups, dependent on the choice of the isocyanide. This was performed in order to vary the polarity of the polymer as well, so the reaction was tested with methyl isocyanoacetate $\mathbf{6}$ and five repeating units per arm to finally obtain star-shaped homopolymer P13. The functionalization with PEG isocyanide 7 and PEG aldehyde 8 resulted in a hydrophilic shell around the hydrophobic core, leading to amphiphilic four-armed star-shaped block 

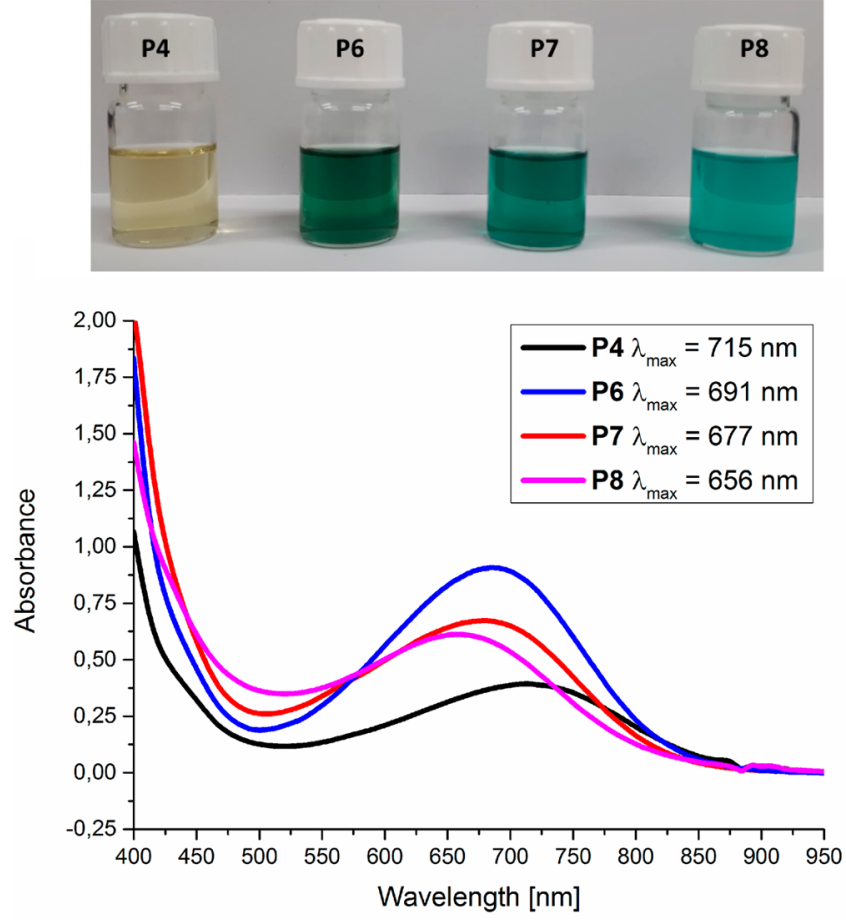

Figure 4. Pictures (above) and UV/vis spectra (below) of the encapsulation of Reichardt's Dye in DCM by reduced and oxidized star-shaped block copolymers P4, P6, P7, and P8 showing different wavelength maxima, due to their different polarity and due to the solvatochromism effect of the encapsulated dye.

copolymer P14. The previously synthesized star-shaped homopolymer P9 was used as four-armed acid component within the Passerini reaction.

Characterization of the Unimolecularity of the StarShaped Block Copolymers via DLS. The unimolecularity of P4 and P5 was already confirmed in our previous study ${ }^{14}$ via dynamic light scattering (DLS) measurements. Current DLS measurements of P6, P7, P8, and P14 (SI, Figures S24-S27) also confirmed the unimolecular behavior. The values measured in DCM $(4.2-5.6 \mathrm{~nm})$, compared to values obtained in water $(7.5-8.7 \mathrm{~nm})$, were again slightly lower, due to the different swelling behavior of these polymers in the different solvents. Furthermore, it could be shown that the diameter of the fourarmed star shaped block copolymer P14 is slightly higher compared to the three-armed analogues.

Polarity Characterization and Dye Encapsulation Tests of Three-Armed Star-Shaped Polymers. Thereafter, the octanol-water partition coefficients of the three-armed starshaped block copolymers P4, P6, P7, and P8 were determined using RP-HPLC. Figure 2 shows the obtained results for P4, P6, P7, and P8 compared to the two dyes Orange II and Para Red. Oxidation of the star-shaped polymers increased their polarity, as indicated by a negative value of $\log k$ of P7 and P8. Using methyl isocyanoacetate 6 instead of tert-butyl isocyanide $\mathbf{5}$ also increased the polarity slightly. Interestingly, Para Red was of a similar polarity as the starting polymers, and Orange II showed a comparable polarity to the oxidized polymers. In a further test, the encapsulation of the star-shaped block copolymers P4, P6, P7, and P8, with different polarity, using water insoluble Para Red in water and Orange II (insoluble in DCM) in DCM, was investigated by UV/vis measurements (Figure 3). The encapsulation was expected to be more efficient if the polarity of polymers and dye were similar. It could thus be
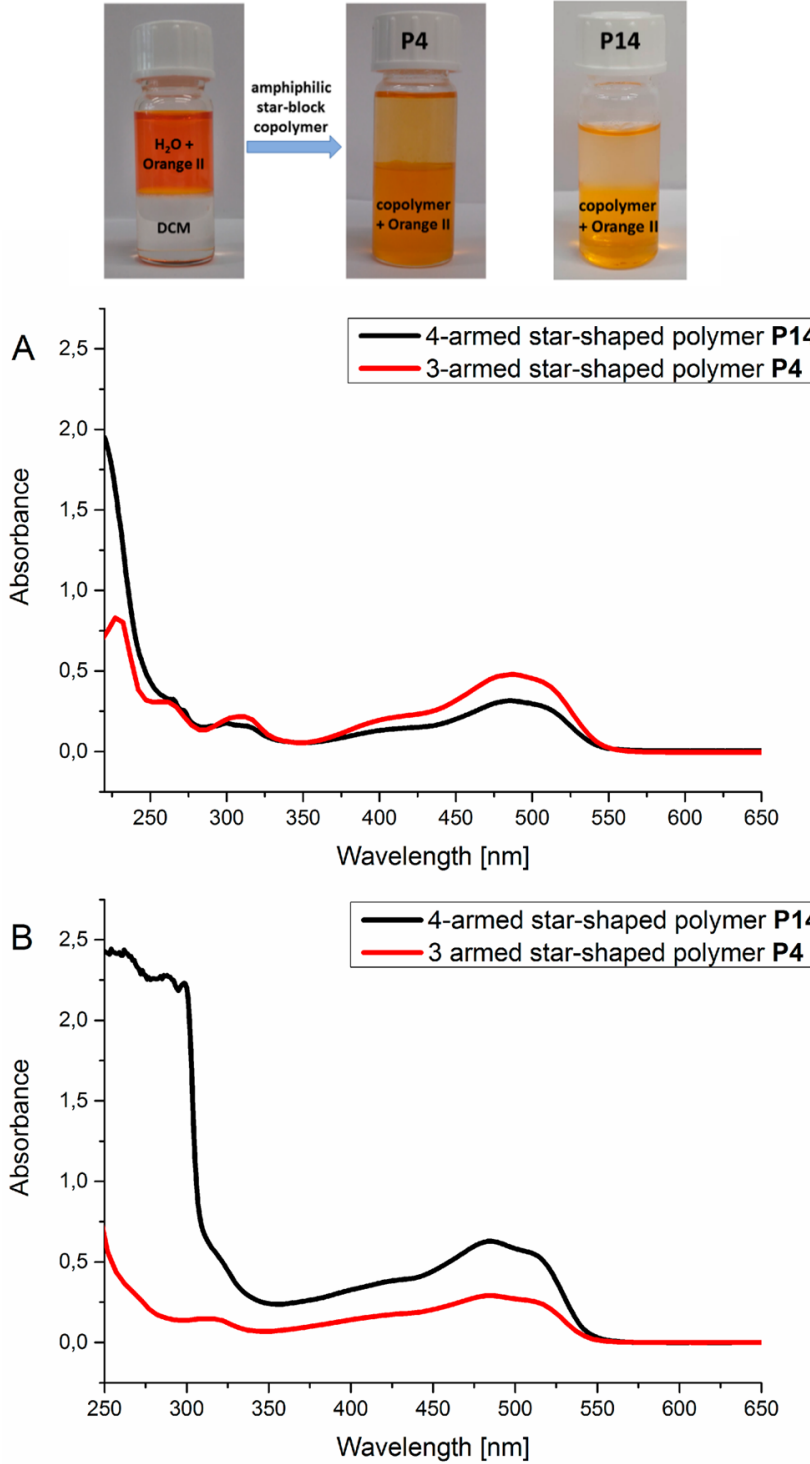

Figure 5. Picture (above) and UV/vis spectra (A, B) of the encapsulation and phase transfer of Orange II from the water phase to the DCM phase by three-armed star-shaped block copolymer P4 and four-armed star-shaped block copolymer P14 (A: absorbance of Orange II in water, B: absorbance of Orange II in DCM).

shown that the encapsulation of the more polar Orange II was more efficient using oxidized star-shaped block copolymers P7 and P8. On the other hand, the encapsulation of Para Red was higher with the nonoxidized star-shaped block copolymers P4 and P6. Due to the insolubility of the dye in DCM, it was not possible to record a calibration curve, which is why these results are relative to each other in this case. Summarizing, this is a clear proof that the polarity of the star-shaped polymers can be tuned by using different polar isocyanides and by oxidizing the polymer backbone. Furthermore, it could be shown that the polarity of the star-shaped polymers significantly affected the encapsulation behavior.

The same set of polymers were used again to visualize the polarity within a solvatochromism experiment. The effect of solvatochromism describes the ability of a chemical substrate to change its color depending on the polarity of the solvent in which it is dissolved. ${ }^{28}$ The Reichardt's dye shows one of the largest solvachromic effects with a color change over the whole 

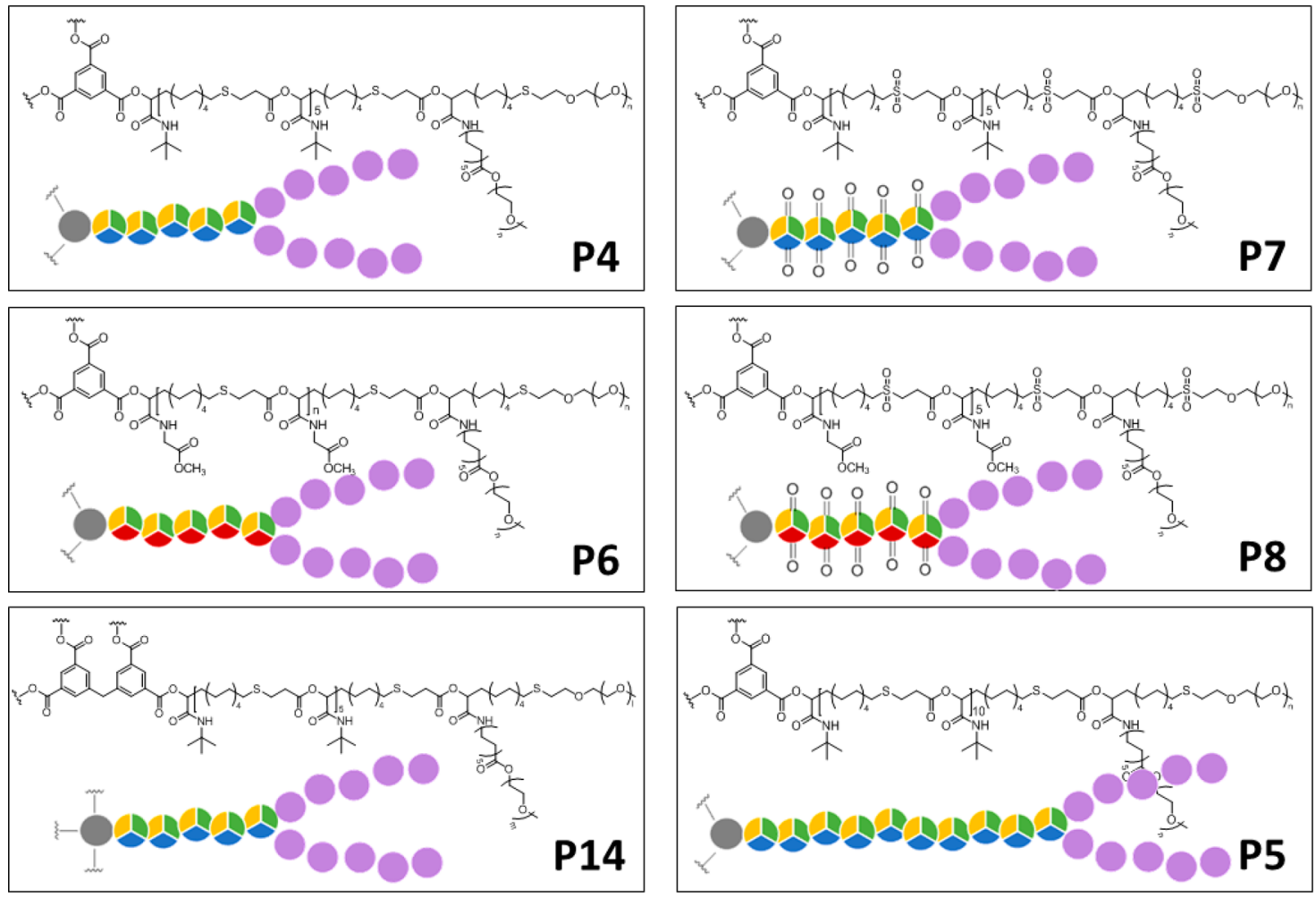

Figure 6. Schematic representation of the star-shaped block copolymers which were used for the encapsulation tests

visible spectrum. ${ }^{29}$ The star-shaped block copolymers P4, P6, $\mathbf{P 7}$, and P8 were able to encapsulate this dye and, due to the different microenvironment within their core, the different colors were made visible through the solvatochromism effect of the dye (Figure 4). These visual results were confirmed by UV/vis absorption experiments, which showed different wavelength maxima, due to the different polarity of the star-shaped block copolymers. The higher the polarity, the lower was the wavelength maximum.

Comparison of the Encapsulation Behavior of FourArmed and Three-Armed Star-Shaped Polymers. Furthermore, it was shown that not only the polarity has an influence on the encapsulation behavior, but also the number of arms. Therefore, the dye Orange II was added to a biphasic water/ DCM system as described above (Figure 5). Orange II is soluble in water but insoluble in DCM. After adding the amphiphilic four-armed star-shaped block copolymer P14, most of the dye was encapsulated and phase-transferred to the organic phase. These results were compared to previous results of amphiphilic three-armed star-shaped block copolymer P4 in former studies. ${ }^{14}$ The phase transfer behavior was additionally investigated by a $\mathrm{UV} /$ vis experiment. In both solvent phases, the absorption was measured separately, and it could be shown that P14 could encapsulate more dye, due to the higher number of arms. The absorption of the dye, using P14, was higher in DCM, whereas it was lower in the water phase as compared to the results for P4.

Drug Loading, Encapsulation Efficiency, and Drug Release Studies. Azithromycin is a semisynthetic macrolide antibiotic, which is extensively used in the treatment of respiratory tract and skin infections. ${ }^{30}$ This drug is slightly watersoluble, $^{31}$ with a similar solubility profile to many approved active pharmaceutical ingredients, and has good bioavailability in both oral and injectable formulations. However, for pediatric settings, where dosing is more critical and the gap between toxic and minimum therapeutic levels is much lower, a sustained release formulation of azithromycin is highly desirable. ${ }^{32}$ Owing to the widespread existing use of polyester materials in controlled release formulations, ${ }^{33}$ we therefore were interested in the ability of the Passerini-3CR star-shaped block copolymers to encapsulate the azithromycin molecule in a unimolecular micelle formulation, and to release it under physiologically relevant conditions. Azithromycin was here thus tested as a hydrophobic drug model.

The azithromycin loading, encapsulation efficiency and polymer:drug molar ratio were determined for the star-shaped block copolymers P4, P5, P6, P7, P8, P14 (Figure 6) and summarized in Table 1.

Table 1. Drug Loading and Encapsulation Efficiency Data of P4, P5, P6, P7, P8, and $14^{a}$

\begin{tabular}{cccc}
$\begin{array}{c}\text { star-shaped block } \\
\text { copolymer }\end{array}$ & $\begin{array}{c}\text { drug loading } \\
(\text { wt \%) } \pm \text { SD }\end{array}$ & $\begin{array}{c}\text { encapsulation } \\
\text { efficiency }(\%) \pm S D\end{array}$ & $\begin{array}{c}\text { molar ratio } \\
\text { pol/Az }\end{array}$ \\
P4 & $8.0 \pm 1.24$ & $8.09 \pm 2.14$ & $1: 1.35$ \\
P5 & $25.3 \pm 1.06$ & $30.37 \pm 3.24$ & $1: 5$ \\
P6 & $8.9 \pm 0.4$ & $11.74 \pm 1.78$ & $1: 1.32$ \\
P7 & $17.7 \pm 0.8$ & $44.13 \pm 2.03$ & $1: 2.68$ \\
P8 & $21.9 \pm 1.3$ & $38 \pm 2.95$ & $1: 3.36$ \\
P14 & $35 \pm 0.6$ & $42.06 \pm 1.2$ & $1: 6$ \\
${ }^{a} \mathrm{SD}$, standard deviation; Pol/Az, polymer/azithromycin. & \\
\hline
\end{tabular}

The highest drug loading was observed for P14; this confirmed that the encapsulation ability was affected by the number of arms of the star-shaped block copolymer. P5 results further confirmed how the drug encapsulation could be improved by increasing the number of homopolymer-repeating units. P4, P6, P7, and P8 data showed how the drug loading could be driven, not only by the hydrophobic, but also by the hydrogenbonding interactions. The high drug encapsulation observed for P7 and P8 (compared to P4 and P5, respectively) suggested 
that the sulfone groups were interacting as hydrogen bond acceptors with the seven hydrogen bond donors of azithromycin. In contrast, P4 and P6 showed low drug encapsulation.

The drug release profile was studied at $\mathrm{pH} 7.4$ (blood $\mathrm{pH}$ ) and 5 (approximate lysosomal $\mathrm{pH}$ ) and is shown in Figure 7.

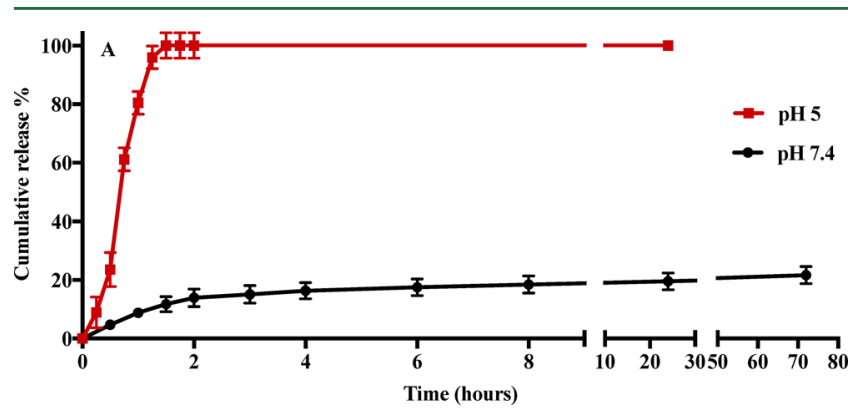

Figure 7. Analysis of azithromycin release from P14 Passerini unimolecular micelles $\mathrm{pH} 5$ lysosome mimicking and $\mathrm{pH} 7.4$ blood mimicking.

It was found that at $\mathrm{pH} 7.4$ only $20 \%$ of the loaded azithromycin was released in $5 \mathrm{~h}$ and the remaining content was retained over 3 days. It was observed that at $\mathrm{pH} 5$ the drug was completely released within $2 \mathrm{~h}$. These results suggested that azithromycin, as a weakly dibasic antibiotic, ${ }^{34}$ was protonated at acidic $\mathrm{pH}$ and thus released faster than at $\mathrm{pH}$ 7.4. These studies showed how P14 could potentially retain the loaded drug during circulation in the bloodstream (i.e., $\mathrm{pH}$ 7.4), but selectively and completely release it inside acidified intracellular compartments (endo/lysosomes, $\mathrm{pH} \sim 5$ ) or in regions of enhanced acidity at infection sites. As a consequence, the acidic $\mathrm{pH}$ could potentially trigger the drug release mimicking $\mathrm{pH}$-responsive polymers, which are attracting increasing attention. These polymers are generally characterized by pendant groups, which become ionized when the $\mathrm{pH}$ increased above their acidic dissociation constant $\left(\mathrm{pK}_{\mathrm{a}}\right)$ leading to programmable swelling behavior. ${ }^{35}$ Synthetic polymers, such as poly(diethylaminoethyl methacrylate) PDEAEMA and poly(acrylamide) PAAm, can be ionized at low $\mathrm{pH}$ and thus behave as acidic triggered polymers. ${ }^{35}$ Alternatively, natural polymers, such as proteins, can display a $\mathrm{pH}$-responsive behavior when the $\mathrm{pH}$ is far from their isoelectric point. ${ }^{35}$ For example, albumin bound paclitaxel delivery systems perform the drug release upon protein denaturation in the acidic intracellular endosome. ${ }^{36}$

Viability, Bacterial Susceptibility Assays, and Cellular Uptake. A CellTiter-Fluor cell viability assay was performed to assess the effects of star-shaped block copolymer P14 in THP-1 macrophage differentiated cells over an incubation period of $72 \mathrm{~h}$. Untreated cells, cells exposed to highly lytic surfactants and polymer solutions were tested as controls. The cytotoxic effect of nanoformulations in THP-1 differentiated macrophages was reported to be tested in a range of concentration between 0.01 and $0.1 \mathrm{mg} / \mathrm{mL}$, whereas, here, five concentrations (ranging from 0.1 to $1 \mathrm{mg} / \mathrm{mL}$ ) of $\mathbf{P 1 4}$ were tested. The $1 \mathrm{mg} / \mathrm{mL}$ starshaped block copolymer P14-treated cells showed a protease activity similar to the untreated cells. This suggested that P14 did not have any cytotoxic effect and was well-tolerated by THP-1 differentiated macrophages (Figure 8).

The antibiotic activity of the free and encapsulated azithromycin in P14 was assessed by performing a susceptibility assay with the common opportunistic pathogen Staphyloccocus aureus (Figure 9). Four concentrations of antibiotic (ranging from 0.1 to $100 \mu \mathrm{g} / \mathrm{mL}$ ) were tested and the bacteria growth was

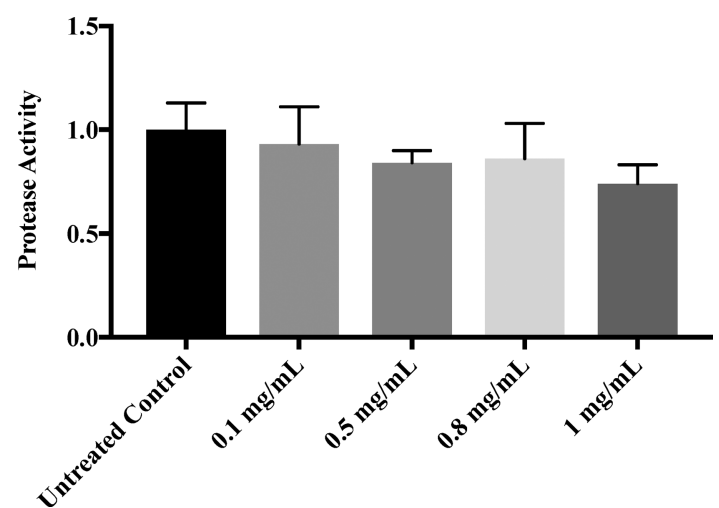

Figure 8. Viability assay showing the protease activity of differentiated THP-1 cells treated with different concentrations of P14. Untreated control: cells untreated with P14.

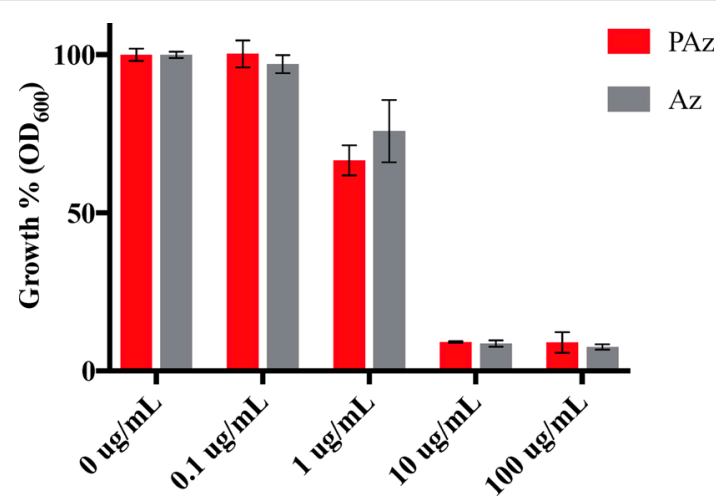

Figure 9. Effect of encapsulated Azithromycin on Staphyloccocus aureus growth. Bacteriostatic activity of serial concentrations $(100-0.1 \mu \mathrm{g} / \mathrm{mL})$ of free (Az) or P14-encapsulated Azithromycin (PAz) were assessed in TSB cultures. Values given are averages from three different cultures \pm standard deviation and correspond to the area under the curve derived from plotting single $\mathrm{OD}_{600}$ measurements over time $(24 \mathrm{~h})$ and as percentage of the corresponding growth obtained in the untreated controls (set at 100\%). Controls wells $\mathrm{Az} 0 \mu \mathrm{g} / \mathrm{mL}$ and $\mathrm{Paz} 0 \mu \mathrm{g} / \mathrm{mL}$ were supplemented with solvent or only P14, respectively.

assessed by quantifying the optical density $\left(\mathrm{OD}_{600}\right)$. It was found that the encapsulated and free azithromycin $(1 \mu \mathrm{g} / \mathrm{mL})$ showed $60 \%$ of bacteria growth and at $100 \mu \mathrm{g} / \mathrm{mL}$ only $10 \%$. These results showed an antibiotic activity in accordance with the literature, where it was reported that the breakpoint of azithromycin for susceptibility against Staphylococcus aureus occurs at a MIC less than or equal to $200 \mu \mathrm{g} / \mathrm{mL}$. $^{38}$ It was also observed that the bacteriostatic activity of the encapsulated drug was the same of the free drug, suggesting that the encapsulation did not affect the azithromycin antibiotic activity. This assay was repeated three times with reproducible results; untreated wells and wells supplemented with solvent or polymer were set as controls.

Confocal laser scanning microscopy was performed in order to assess the intracellular localization of the cargo carried by P14 unimolecular micelles. Differentiated THP-1 macrophages were incubated for $1 \mathrm{~h}$ with P14 unimolecular micelles, loaded with Oregon-green $(100 \mu \mathrm{g} / \mathrm{mL})^{26}$ (Figure 10). A Z-stack acquisition performed with Carl Zeiss LSM 700 BW microscope allowed acquiring zoom and $X / Y$ axes sections of the immobilized differentiated THP-1 macrophages. These images (Figure 10A-C) showed how the green fluorescence (Oregongreen loaded micelles) was not overlapped with the red 


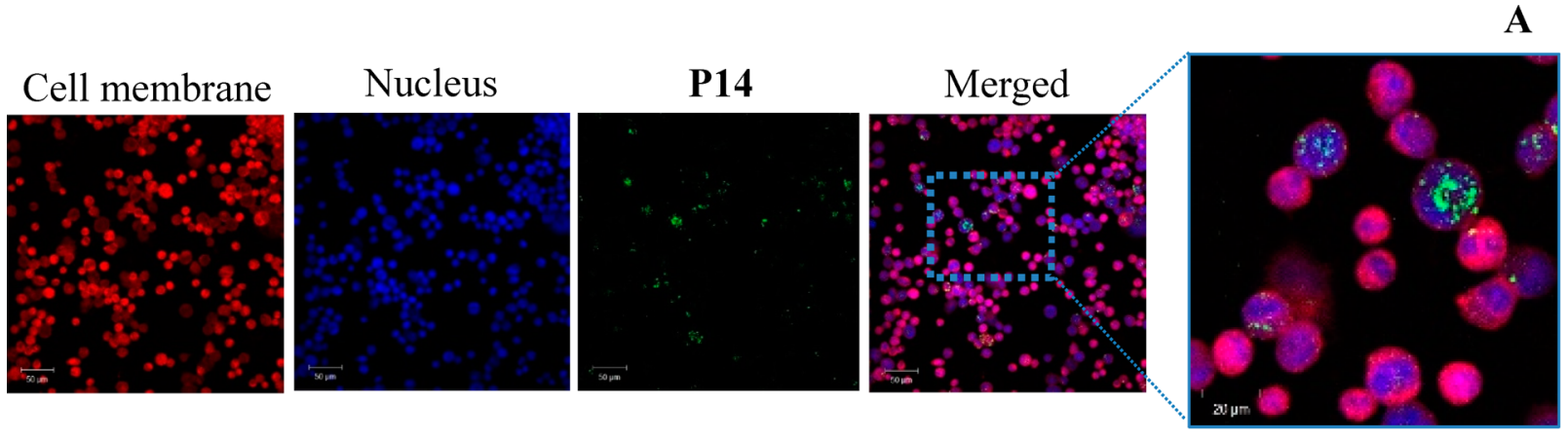

F-actin

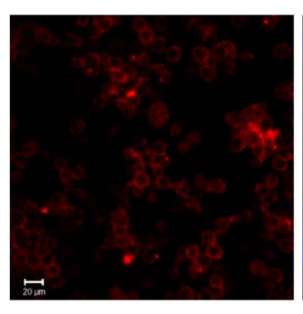

P14 and F-actin

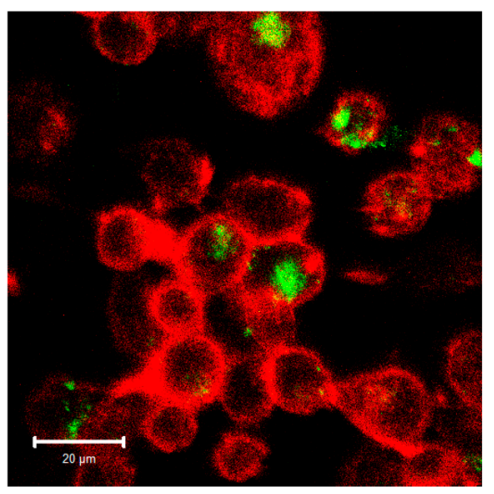

Nucleus

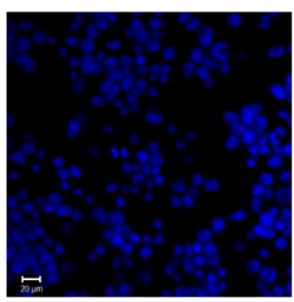

P14

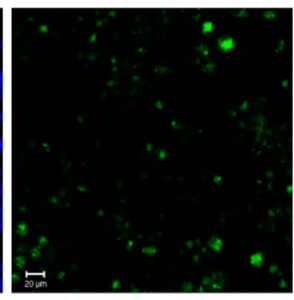

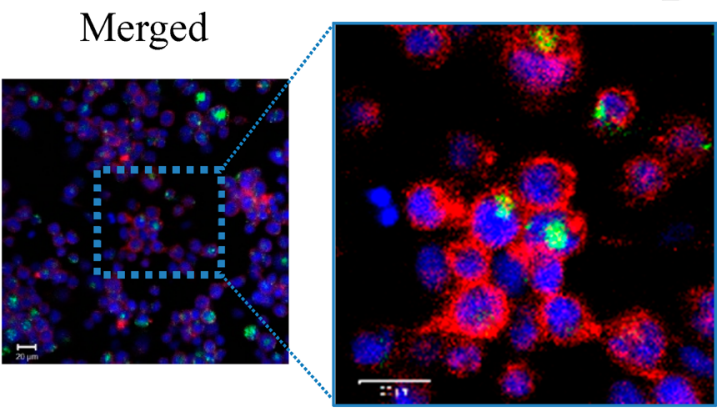

C
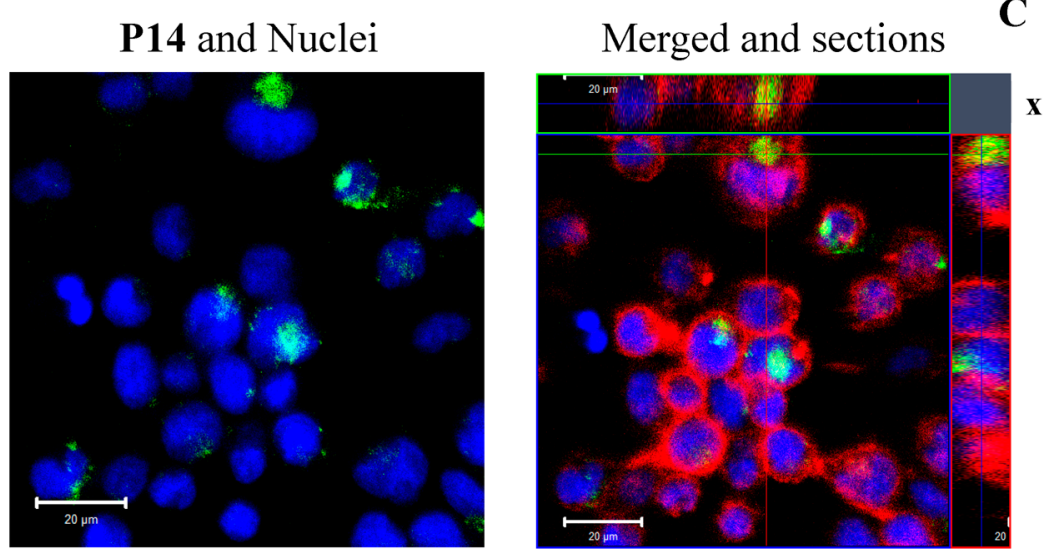

$\mathbf{y}$

Figure 10. Confocal laser scanning microscopic images of cellular uptake in macrophage differentiated THP-1 cells cultured with Oregon-green loaded P14 unimolecular micelles. (A) Staining protocol I (SI, page 35) and (B) Staining protocol II (SI, page 35). (C) Figure B section and zoom. Nuclei of cells were stained with Hoechst (blue fluorescence), cells membranes were stained with CellMask deep red plasma membrane stain (red fluorescence), and F-actin was stained with Alexa Fluor 647 Phalloidin (red fluorescence).

fluorescence of the F-Actin or of the membrane and with the blue fluorescence of the nuclei. Figure 10C clearly suggested that the unimolecular P14 micelle was internalized by the differentiated THP-1 macrophages and then localized in the cytoplasm. As a consequence, the unimolecular P14 micelle was able to deliver its cargo inside the cells.

\section{CONCLUSIONS}

In conclusion, we have synthesized a library of amphiphilic starshaped block copolymers via Passerini-3CR reactions. The polarity of the hydrophobic block was increased by oxidizing the sulfide groups to sulfones leading to the encapsulation of hydrophobic and hydrophilic molecules, respectively. It was found that the encapsulation ability was not only related to the polarity but also to the number of arms of the hydrophobic core of the star-shaped copolymers. For the antimicrobial drug azithromycin, the drug loading was found to be $35 \mathrm{~mol} \%$, which, considering the physical properties of azithromycin are analogous to many other active pharmaceutical ingredients, suggests a potential biomedical application for the amphiphilic star-shaped block copolymers presented in this study. The polymers were found to be well tolerated by macrophages, which are the first cells to internalize most injected formulations and the sanctuary sites for many bacterial pathogens. Furthermore, the Passerini polymers were able to retain azithromycin within their unimolecular micellar structure at $\mathrm{pH}$ levels found in the bloodstream, but release the drug under acidic $\mathrm{pH}$ values similar to those in intracellular digestive compartments. Finally, the activity of the drug when delivered from the unimolecular micelle formulations was fully retained in terms of bacterial cell kill, as susceptibility assays using the common pathogen Staphylococcus aureus showed. In conclusion, our results clearly 
suggest the investigated unimolecular micelles have potential as easy-to-synthese, cytocompatible drug delivery systems, with good drug loading and release properties.

\section{ASSOCIATED CONTENT}

\section{S Supporting Information}

The Supporting Information is available free of charge on the ACS Publications website at DOI: 10.1021/acs.biomac.8b00592.

Full synthetic procedures, characterization data, and further experimental details (PDF).

\section{Accession Codes}

All raw data created during this research are openly available from the corresponding author (cameron.alexander@ nottingham.ac.uk) and at the University of Nottingham Research Data Management Repository (https://rdmc. nottingham.ac.uk/, DOI: 10.17639/nott.351), and all analyzed data supporting this study are provided as Supporting Information accompanying this paper.

\section{AUTHOR INFORMATION}

\section{Corresponding Authors}

*E-mail: m.a.r.meier@kit.edu. Web: www.meier-michael.com. Twitter: @AK_Meier.

*E-mail: cameron.alexander@nottingham.ac.uk.

\section{ORCID}

Steven M. Howdle: 0000-0001-5901-8342

Cameron Alexander: 0000-0001-8337-1875

Michael A. R. Meier: 0000-0002-4448-5279

\section{Author Contributions}

The manuscript was written through contributions of all authors. All authors have given approval to the final version of the manuscript.

\section{Author Contributions}

${ }^{\ddagger}$ These authors contributed equally.

\section{Funding}

This work was supported by the Engineering and Physical Sciences Research Council (Grant Numbers EP/N03371X/1, $\mathrm{EP} / \mathrm{H} 005625 / 1, \mathrm{EP} / \mathrm{N006615/1}$, and EP/L013835/1); Grant Names: EPSRC Programme Grant in Next Generation Biomaterials Discovery, the Royal Society (Wolfson Research Merit Award WM150086), and the University of Nottingham. We also thank Professor A. M. Ghememaghami for the use of cell culture facilities, Professor M. R. Alexander for helpful discussions, Elizabeth Hufton for expert support in the EPSRC Next Generation Biomaterials Discovery Programme Grant, and Patricia Monteiro, Arsalan Latif, and Mohammad Al-Natour for their practical assistance and advice. Furthermore, we thank Professor Podlech and his group for access to the UV/vis equipment, Professor Bräse and his group for the access to the RP-HPLC, and Rebecca Seim for her help with the monomer synthesis.

Notes

The authors declare no competing financial interest.

\section{ABBREVIATIONS}

ACN, acetonitrile; CCR2, CC chemokine receptor 2; CCL2, CC chemokine ligand 2; CCR5, CC chemokine receptor 5; Passerini-3CR, Passerini three components reaction; THF, tetrahydrofuran; TLC, thin layer chromatography.

\section{REFERENCES}

(1) Zhu, J.; Bienaymé, H. Multicomponent Reactions; Wiley-VH Verlag GmbH \& Co. KGaA, 2006.

(2) Zhu, J.; Wang, Q.; Wang, M. Multicomponent Reactions in Organic Synthesis; Wiley-VH Verlag GmbH \& Co. KGaA, 2014.

(3) Llevot, A.; Boukis, A. C.; Oelmann, S.; Wetzel, K.; Meier, M. A. $\mathrm{R}$. An Update on Isocyanide-Based Multicomponent Reactions in Polymer Science. Top. Curr. Chem. 2017, 375, 66.

(4) Sehlinger, A.; Meier, M. A. R. Passerini and Ugi Multicomponent Reactions in Polymer Science. Adv. Polym. Sci. 2014, 269, 61-86.

(5) Passerini, M. Gazz. Chim. Ital 1921, 51, 181.

(6) Passerini, M.; Simone, L. Gazz. Chim. Ital 1921, 51, 126.

(7) Kreye, O.; Toth, T.; Meier, M. A. Introducing multicomponent reactions to polymer science: Passerini reactions of renewable monomers. J. Am. Chem. Soc. 2011, 133 (6), 1790-2.

(8) Deng, X.-X.; Li, L.; Li, Z.-L.; Lv, A.; Du, F.-S.; Li, Z.-C. Sequence Regulated Poly(ester-amide)s Based on Passerini Reaction. ACS Macro Lett. 2012, 1 (11), 1300-1303.

(9) Zhang, L.-J.; Deng, X.-X.; Du, F.-S.; Li, Z.-C. Chemical Synthesis of Functional Poly(4-hydroxybutyrate) with Controlled Degradation via Intramolecular Cyclization. Macromolecules 2013, 46 (24), 95549562.

(10) Meier, M. A. R.; Schubert, U. S. Fluorescent sensing of transition metal ions based on the encapsulation of dithranol in a polymeric core shell architecture. Chem. Commun. 2005, 36, 46104612.

(11) Schramm, O. G.; Pavlov, G. M.; van Erp, H. P.; Meier, M. A. R.; Hoogenboom, R.; Schubert, U. S. A Versatile Approach to Unimolecular Water-Soluble Carriers: ATRP of PEGMA with Hydrophobic Star-Shaped Polymeric Core Molecules as an Alternative for PEGylation. Macromolecules 2009, 42 (6), 1808-1816.

(12) Heise, A.; Hedrick, J. L.; Frank, C. W.; Miller, R. D. Starlike Block Copolymers with Amphiphilic Arms as Models for Unimolecular Micelles. J. Am. Chem. Soc. 1999, 121 (37), 8647-8648.

(13) Fan, X.; Li, Z.; Loh, X. J. Recent development of unimolecular micelles as functional materials and applications. Polym. Chem. 2016, 7 (38), 5898-5919.

(14) Oelmann, S.; Solleder, S. C.; Meier, M. A. R. Controlling molecular weight and polymer architecture during the Passerini three component step-growth polymerization. Polym. Chem. 2016, 7 (10), $1857-1860$.

(15) Oelmann, S.; Meier, M. A. R. Synthesis and unimolecular micellar behavior of amphiphilic star-shaped block copolymers obtained via the Passerini three component reaction. RSC Adv. 2017, 7 (71), 45195-45199.

(16) Solleder, S. C.; Zengel, D.; Wetzel, K. S.; Meier, M. A. R. A Scalable and High-Yield Strategy for the Synthesis of SequenceDefined Macromolecules. Angew. Chem., Int. Ed. 2016, 55 (3), 12041207.

(17) Unverferth, M.; Meier, M. A. R. Tuning the polarity of ADMET derived star-shaped polymers via thiol-ene chemistry. Polymer 2014, 55 (22), 5571-5575.

(18) Andersson, J. T.; Schräder, W. A Method for Measuring 1Octanol-Water Partition Coefficients. Anal. Chem. 1999, 71 (16), 3610-3614.

(19) OECD, Test No. 117: Partition Coefficient (n-octanol/water), HPLC Method. OECD Publishing.

(20) British Pharmacopoeia. https://www.pharmacopoeia.com/ search?text=azithromycin.

(21) Anderson, J. A.; Lamichhane, S.; Remund, T.; Kelly, P.; Mani, G. Preparation, characterization, in vitro drug release, and cellular interactions of tailored paclitaxel releasing polyethylene oxide films for drug-coated balloons. Acta Biomater. 2016, 29, 333-351.

(22) Carreira, A. C.; Almeida, R. F. M.; Silva, L. C. Development of lysosome-mimicking vesicles to study the effect of abnormal accumulation of sphingosine on membrane properties. Sci. Rep. 2017, 7 (1), 3949.

(23) Gulfam, M.; Matini, T.; Monteiro, P. F.; Riva, R.; Collins, H.; Spriggs, K.; Howdle, S. M.; Jérôme, C.; Alexander, C. Bioreducible 
cross-linked core polymer micelles enhance in vitro activity of methotrexate in breast cancer cells. Biomater. Sci. 2017, 5, 532-550.

(24) Dollinger, C.; Ciftci, S.; Knopf-Marques, H.; Guner, R.; Ghaemmaghami, A. M.; Debry, C.; Barthes, J.; Vrana, N. E. Incorporation of resident macrophages in engineered tissues: Multiple cell type response to microenvironment controlled macrophage-laden gelatine hydrogels. J. Tissue Eng. Regener. Med. 2018, 12 (2), 330-340.

(25) Riss, T. L.; Moravec, R. A.; Niles, A. L.; Duellman, S.; Benink, H. A.; Worzella, T. J.; Minor, L. In Cell Viability Assays; Sittampalam, G. S., Coussens, N. P., Brimacombe, K., et al., Eds.; Eli Lilly \& Company and the National Center for Advancing Translational Sciences, 2013 (updated 2016 Jul 1).

(26) Hall, I. H.; Schwab, U. E.; Ward, E. S.; Rublein, J. C.; Butts, J. D.; Ives, T. J. Human THP-1 monocyte uptake and cellular disposition of 14C-grepafloxacin. J. Infect. Chemother. 2004, 10 (1), 11-8.

(27) Sehlinger, A.; Schneider, R.; Meier, M. A. R. Passerini addition polymerization of an AB-type monomer - A convenient route to versatile polyesters. Eur. Polym. J. 2014, 50, 150-157.

(28) Kreye, O.; Oelmann, S.; Meier, M. A. R. Renewable AromaticAliphatic Copolyesters Derived from Rapeseed. Macromol. Chem. Phys. 2013, 214 (13), 1452-1464.

(29) Machado, V. G.; Machado, C. An Easy and Versatile Experiment to Demonstrate Solvent Polarity Using Solvatochromic Dyes. J. Chem. Educ. 2001, 78 (5), 649.

(30) Matzneller, P.; Krasniqi, S.; Kinzig, M.; Sorgel, F.; Huttner, S.; Lackner, E.; Muller, M.; Zeitlinger, M. Blood, tissue, and intracellular concentrations of azithromycin during and after end of therapy. Antimicrob. Agents Chemother. 2013, 57 (4), 1736-42.

(31) Azithromycin. https://www.drugbank.ca/drugs/DB00207.

(32) Kauss, T.; Gaudin, K.; Gaubert, A.; Ba, B.; Tagliaferri, S.; Fawaz, F.; Fabre, J.-L.; Boiron, J.-M.; Lafarge, X.; White, N. J.; Olliaro, P. L.; Millet, P. Screening paediatric rectal forms of azithromycin as an alternative to oral or injectable treatment. Int. J. Pharm. 2012, 436 (1), 624-630.

(33) Danhier, F.; Ansorena, E.; Silva, J. M.; Coco, R.; Le Breton, A.; Préat, V. PLGA-based nanoparticles: An overview of biomedical applications. J. Controlled Release 2012, 161 (2), 505-522.

(34) Hand, W. L.; Hand, D. L. Characteristics and mechanisms of azithromycin accumulation and efflux in human polymorphonuclear leukocytes. Int. J. Antimicrob. Agents 2001, 18 (5), 419-25.

(35) Fan, X.; Chung, J. Y.; Lim, Y. X.; Li, Z.; Loh, X. J. Review of Adaptive Programmable Materials and Their Bioapplications. ACS Appl. Mater. Interfaces 2016, 8 (49), 33351-33370.

(36) Ding, C.; Li, Z. A review of drug release mechanisms from nanocarrier systems. Mater. Sci. Eng., C 2017, 76, 1440-1453.

(37) Berger, E.; Breznan, D.; Stals, S.; Jasinghe, V. J.; Gonçalves, D.; Girard, D.; Faucher, S.; Vincent, R.; Thierry, A. R.; Lavigne, C. Cytotoxicity assessment, inflammatory properties, and cellular uptake of Neutraplex lipid-based nanoparticles in THP-1 monocyte-derived macrophages. Nanobiomedicine 2017, 4, 1849543517746259.

(38) Zuckerman, J. M. Macrolides and ketolides: azithromycin, clarithromycin, telithromycin. Infectious Disease Clinics of North America 2004, 18 (3), 621-649. 